Mediaciones Sociales

ISSN-e: 1989-0494

EDICIONES

http://dx.doi.org/10.5209/MESO.58122

COMPLUTENSE

\title{
El sentido social de la mediación entre las marcas y las audiencias
}

Curtich, Javier; Fuentes, Mauro A.; García, Yolanda; Toca, Antonio (2011) La comunicación y el sentido común en la era de la Internet Social. Profit editorial, 296 pp. ISBN: 978-84-92956-27-2.

Los autores de esta obra son profesionales expertos del marketing y de la comunicación que forman parte del equipo directivo de Tinkle, una compañía independiente de comunicación y social media comprometida con el desarrollo y la innovación ${ }^{1}$. Como producción colectiva, Sentido Social aspira a ser una guía profesional y útil para quienes desean escuchar con eficiencia $y$ comunicar con efectividad en las redes sociales. A las empresas y técnicos de la comunicación, desde el marketing hasta las relaciones públicas, brinda claves sobre el momentum que suponen los Social Media ${ }^{2}$ a las prácticas de la comunicación masiva y en las relaciones entre las marcas y audiencias, entre compañías, usuarios/consumidores.

Este libro parte de una premisa que ya

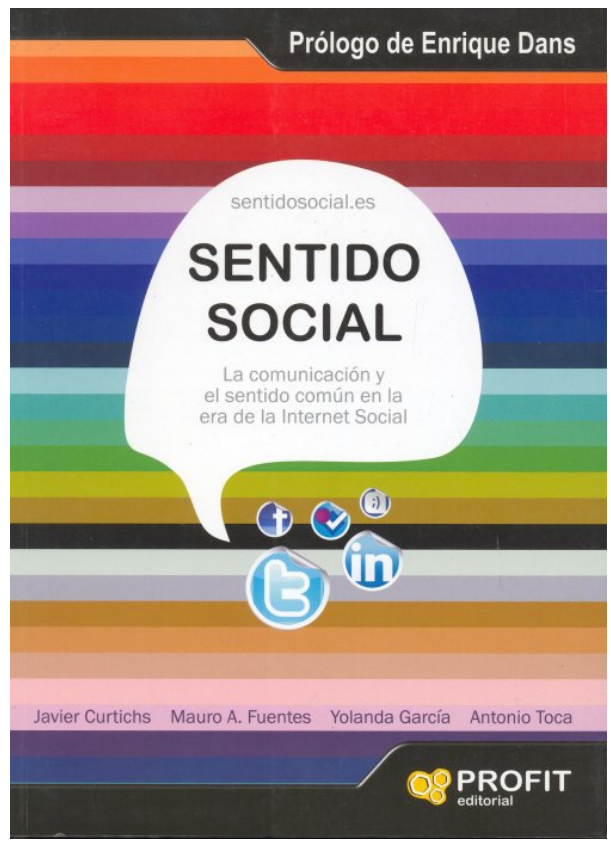
nadie puede cuestionar: la transformación tan fuerte y vertiginosa que ha supuesto la aparición de la Internet Social en la última década, ha provocado un cambio radical sobre las ya afectadas bases industriales/masivas de la comunicación mediática. Con un nuevo escenario, donde las audiencias se han empoderado de habilidades y capacidades técnicas para el diálogo en la Red, los actores principales

\footnotetext{
${ }^{1}$ Javier Curtich es Consejero Delegado y fundador de la firma y ha desarrollado su carrera profesional como comunicador en diferentes organizaciones. Mauro Antonio Fuentes es Director de Social Media de Tinkle, ligado al mundo de Internet desde 1999 y Yolanda García es responsable de Estrategia Digital de Tinkle Barcelona, vinculada al mundo de la comunicación en Internet. Por su parte, Antonio Toca, responsable de Estrategia Digital de Tinkle Madrid, está vinculado a Internet desde 2003.

${ }^{2}$ Los autores del libro entienden por Social Media los sitios donde suceden las conversaciones, hay interacción, se comparten las cosas y se intercambia información.
} 
de la comunicación empresarial tienen que modificar las formas tradicionales de mediación para proseguir tras sus objetivos organizacionales.

La evolución de la web a su carácter social, eso que genéricamente se ha hecho llamar la Web 2.0, es lo que los autores caracterizan como el Sentido Social hoy dispuesto en la Internet. En su establecimiento, el Sentido Social se inicia con el auge de los blogs a mediados de los noventa y luego fue potenciado con la aparición de los foros y redes de interacción y/o información como Facebook y Twitter.

Los autores de Sentido Social exaltan un nuevo episodio en el abordaje de la comunicación empresarial de cara a los objetivos de generar demanda en torno a bienes y servicios, así como en la construcción de la lealtad entre los consumidores/clientes, y la reproducción de la reputación de marca en el mercado. «La Internet Social», y el sustento de su «neutralidad», «permite que alguien desde la libre opinión que siempre ha permitido una sociedad en democracia, diga lo que piensa desde el altavoz que representa cualquiera de los perfiles sociales que maneja». Así las cosas, las empresas no pueden hacer las tradicionales maneras de ejercer el mercadeo y la comunicación con sus mercados, especies de gríngolas que les impida visualizar el horizonte de las emergentes prácticas comunicativas a través de las redes sociales, por ejemplo.

Desde estas trincheras de reconocimiento de los cambios tecnológicos, los autores de Sentido Social proponen una vuelta al ejercicio del "sentido común" para observar el panorama, introducir experiencias de comprensión de esta ágora virtual y así incorporar a las empresas con sus objetivos comerciales en una práctica conversacional que ha probado ser riesgosa pero rentable para quien comprenda sus supuestos éticos e instrumentales: racionalidad + saber escuchar + innovación abierta.

La práctica comunicativa del boca a boca, como en cualquier otra red social del mundo off line, se potencia en las redes tecnológicas, en su instantaneidad y alcance global. Para los autores, constituye una economía en sí misma, donde confluyen capitales sociales que crecen en bancos de confianza, donde la interacción más que depender de los «seis grados de separación» entre quienes habitan la comunidad en línea se sustenta en los «tres grados de influencia», ya que hoy damos mayor crédito a las personas con quien tenemos contactos en Facebook, que a cualquiera de los amigos reales.

Lo anterior supone un nuevo escenario de legitimación en el que personas, empresas, organizaciones civiles, políticas y gubernamentales van confluyendo con la finalidad de apuntalar su capital intangible: bien sea el valor de marca, la confianza de los consumidores, o la gestión de una crisis de servicio, en un escenario de representación que se consolida a una velocidad asombrosa, y donde hay que demostrar cierta habilidad de ubicuidad simbólica. En las claves de este discurso, la incorporación al sentido social pasa por dejarse llevar en el flujo de la «innovación abierta». Esto supone dejar «de encerrarse sobre sí mismo» y colaborar con los demás sujetos de la red para generar nuevo conocimiento.

En su primer capítulo, «Del sentido común al sentido social», se incorporan varios supuestos respecto de la Internet Social, a saber: su basamento en la economía de la confianza, divisa imprescindible en este entorno; el hecho de que la experiencia de los clientes se extiende más allá de la Web de cada marca; el sentido 
social obliga a seguir una estrategia multiplataforma que permita estar en todas las plataformas posibles; en la Internet Social, no sólo hay que buscar la forma de atraer más y más gente, sino que hay que «convertirla»; la Internet Social es un mundo que avanza hacia la transparencia; el mensaje, como en todo proceso de eficiencia comunicativa, lo es casi todo, y que al final todo se resume en «escuchar y sentir qué queremos transmitir». Al cierre de este apartado reseñan algunas prácticas y desviaciones que muchas organizaciones y empresas han asumido a la hora de enfilar esfuerzos en social media.

En el segundo apartado, «Las herramientas del social media», los autores plantean que «las redes sociales las componen las personas que las utilizan, por lo que el primer planteamiento que debe hacerse alguien que quiera comunicar las bondades de sus productos o servicios o, simplemente, sus intereses a través de ellas, es escuchar a esas personas». De esta forma, los autores dan respuesta a las preguntas para qué, cómo y qué escuchar, y ofrecen toda una variedad de herramientas de monitorización, herramientas que sirven para gestionar nuestra presencia y comunicación en las redes sociales, herramientas orientadas a mejorar el SMO (Social Media Optimization) ${ }^{3}$ y herramientas analíticas para poder valorar la estrategia de comunicación en la red. Los autores ofrecen, además, la clave para tener una página web suficientemente social que atraiga al público, así como recomendaciones sobre los diferentes lugares virtuales a los que se pueden mandar los contenidos y sobre las diversas formas que existen para dar voz a los usuarios.

El tercer capítulo, «La economía del boca a boca», representa lo que se da por hecho: los consumidores se han convertido en prosumers ${ }^{4}$ o productoresconsumidores de información que dinamiza la «economía del boca a boca» ${ }^{5}$, donde se valoran cosas, marcas, personas, y reputaciones. Que no es un fenómeno emergente pero que en las redes sociales alcanza una dimensión global. En este sistema de socialización, la comunicación empresarial asume un rol evangelizador (customer evangelist). «Influencia, ruido, sencillez, credibilidad, honestidad, sorpresa y confianza» son conceptos simples sobre los que se asienta la economía del boca a boca que engloban la comunicación y el marketing, palabras que comparten las personas tanto del mundo offline como del de la Internet Social de blogs y redes sociales.

En el siguiente tópico, «El porqué del storytelling», se introduce otra de las transformaciones que ha sufrido la comunicación empresarial: ya no vale con contar las bondades de los productos o servicios de una firma para llamar la atención en las redes, sino que el mediador debe articular un relato convincente y atractivo para su estrategia de contenido. La clave para un buen storytelling: todas las historias que se quieran contar deben enfocarse en las personas, en el acercamiento dialogal uno a uno, ya que la gente compra sentimientos y las sensaciones solo las ofrecen las personas. Para alcanzar al público adecuado, no basta con la exposición en el sitio correcto sino contar con un argumento que

\footnotetext{
${ }^{3}$ El SMO (Social Media Optimization) es la capacidad que tienen nuestras propias páginas de ser enlazadas o compartidas.

${ }^{4}$ Personas que no solo reciben información, sino que la producen y distribuyen entre todos los miembros de su red de contactos.

${ }^{5}$ Los autores utilizan esta expresión en lugar de «de boca en boca» o «el boca-oreja», por la manera en que esta forma de comunicación se traslada en su uso cotidiano de lo offline a lo online.
} 
enganche en el tiempo con historias capaces de atrapar la curiosidad y el deseo sobre la organización/marca.

La importancia de desarrollar una buena estrategia de contenido se recoge en el capítulo cinco: «Los valores y la economía de la estrategia de contenido». La cuestión radica en que en la Internet Social el valor al contenido no se lo da el mediador del mensaje (empresa, institución o particular), sino que lo hacen las personas que componen la red. A lo largo de este capítulo los autores dan respuestas a cuestiones como quién debe desarrollar los contenidos (la figura del estratega de contenido) y cómo hacerlo, y cuál es la clave de un contenido exitoso. Además reflexionan sobre otra consecuencia de los medios sociales en Internet: ya no se puede enfocar la estrategia de comunicación solo en la reputación o en la gestión de crisis. Hay que ser consistentes con el Sentido Social cumpliendo con cinco reglas derivadas del sentido común: escuchar, comprometerse, ser reales, ser respetuosos y disfrutar con la comunicación.

En el capítulo seis, «Viralidad», los autores dan al traste con una creencia generalizada: no existen vídeos ni campañas virales por diseño. Es la audiencia con base al boca a boca, quien se encarga de "viralizar" una acción, un vídeo por Internet. Sin embargo, sí se puede crear un contenido potencialmente viral, siempre que el producto o servicio sea deseable de ser contado en su círculo de influencia.

Otro aspecto muy importante que debe tener en cuenta el mediador de la comunicación es lo que los autores denominan «marca personal» (capítulo siete). Dada la competitividad de los ambientes profesionales, la única forma de diferenciarse en el universo de lo simbólico y del consumo virtual es ganar visibilidad. Entre otros ejemplos, los autores resaltan la marca personal que se ha labrado Enrique Dans, Profesor de Sistemas de Información en IE Business School desde el año 1990 y autor del prólogo de esta obra. Tal y como relatan en el libro, «es una persona que ha posicionado su nombre junto a su especialidad (innovación tecnológica) usando las redes sociales». En su libro Todo va a cambiar. Tecnología y evolución: adaptarse o desaparecer, explica los cambios sociales que la tecnología está trayendo a nuestra forma de comunicarnos y relacionarnos a nivel personal y profesional.

«La vuelta de tuerca al marketing digital» es el título del capítulo ocho, en el que los autores hacen referencia a los cambios en la lógica y estructura del marketing tradicional que ha supuesto la Internet Social, pasando de la tradicional teoría de las P's (Producto, Precio, Promoción, Posicionamiento, Publicidad, Packaging, Permiso, Pasar Información), a la plataforma de las C's de los medios sociales, que implican un cambio en la cultura de la comunicación empresarial (el desarrollo de la Idea). Clientes conectados en tiempo real, Contexto y Convergencia, Comunicación e Información, Colaborar, Compartir, Crear, Coleccionar, Clasificar, Comunicad de Contactos, Conversación y Contenidos).

El capítulo nueve está dedicado a «Analítica Web y ROI». Para el momento de la publicación de Sentido Social, Septiembre de 2010, era patente la ausencia de un consenso para medir el retorno sobre las inversiones en social media. Eso sí, su capacidad de influencia versus los costos de inversión que se aplican no han hecho de la consagración de un protocolo de análisis un obstáculo real para el cambio de rentabilidad. Además la publicidad tradicional en sus formatos tradicionales más 
costoso como la publicidad televisiva, han demostrado ya que esconde unos cuántos «actos de fe» en su nomenclatura analítica de alcance e impacto.

En la pesquisa de unidades que permitan cuantificar la efectividad y alcance de las campañas de comunicación en la Internet Social, los autores rescatan el modelo de ROI (Retorno sobre la Inversión) como referente de un valor estimado sobre una reacción concreta y a cada una de las acciones ejecutadas.

Con la irrupción de las redes sociales, el escenario de conversaciones incontroladas se amplía cada día. De esta forma, los autores sugieren varias acciones para evaluar la «reputación on line» a lo largo del capítulo diez. La reputación de una marca es la resultante de todas las acciones que realiza en cada entorno donde se expone. Es la suma de todas las percepciones que general, y como tal no es una construcción cultural homogénea, aunque se puede reconocer que hasta la irrupción de la Internet Social, empresas y marcas tenían mayor control sobre lo que se decía de sí.

En el capítulo once, «Community Manager, una visión», los autores ofrecen una definición nuevo actor de la comunicación empresarial y describen sus competencias y las áreas en las que debe ser soporte. Además, consideran el Community Management más como una competencia de gestión en las comunicaciones organizacionales, lo que aclara mejor los panoramas instrumentales de este profesional.

El último capítulo está dedicado a las «Tendencias y futuro en Social Media», en el que los autores aclaran que, en un entorno tan sujeto a cambios como lo son las redes sociales e Internet, no se pueden hacer predicciones; sin embargo, sí describen algunas tendencias que ya son visibles para la sociedad, como el desarrollo de apps móviles, la consolidación de un protocolo tecnológico para el pago móvil (que acelerará las estrategias de impulso a las ventas), el auge de la publicidad dentro de los terminales móviles, la Geolocalización, el triunfo del real time, la estandarización del Social Search (para conseguir información a través de las redes sociales) y el Social Shopping. Tendencias que, en su mayoría, están orientadas a fomentar, directa o indirectamente, el consumo.

Basándonos en los criterios que sobre la mediación social aportan teóricos como Martín Serrano ${ }^{6}$, esta referencia y en la obra de los autores de Sentido Social, la reflexión orienta el carácter necesario que la Internet Social impone a las prácticas comunicacionales de las organizaciones empresariales, de profesionales y autónomos, quienes deben mediar, utilizando el sentido común, con todas las herramientas que la tecnología pone a su alcance con el objetivo de introducir un modelo de ajuste entre los productos y servicios que ofrecen, los mercados y los consumidores. Esta obra ofrece una visión en tiempo presente de los paradigmas emergentes tras la convergencia tecnológica en las redes. Un universo donde los espacios objetivos, culturales y mentales de la vida cotidiana, que no están ocupados por trabajo, son susceptibles de influencia desde las plataformas dialogales y de relaciones que hoy brinda el ciberespacio y que están al servicios del modelo económico imperante. Tras la lectura de Sentido Social, pareciese que

\footnotetext{
${ }^{6}$ En La mediación social, Martín Serrano nos la define como una «articulación de elementos que pertenecen a diversos planos de la realidad, de modo de introducir en ellos un modelo de orden, un principio de integración y/o ajuste».
} 
la clave del éxito empresarial pasa por la comunicación a través de los Social Media. Pero, ¿hay espacio suficiente en la red para todas las empresas pequeñas y grandes, para todos los emprendedores, para todo el que tenga algo «interesante» qué decir? ¿Sobrevivirán en el futuro quienes no puedan estar dentro de la red?

\section{Bibliografía}

Martín Serrano, M. (1977): La mediación social. Madrid: Akal.

Belén Casas Mas

Universidad Complutense de Madrid bcasasmas@gmail.com

Adolfo Manaure Universidad Complutense de Madrid amanaure@gmail.com 